\title{
Study of Acute Toxicity and the Effect of the Aqueous Extract of a Formulation of Three Edibles Mushrooms on Oxidative Stress Induced in Rats
}

\author{
Etoundi Omgba Cunégonde Blanche ${ }^{1, *}$, Kayo Tayou Cynthia Valère ${ }^{1}$, \\ Mbang Mbarga Audrey Judith ${ }^{1}$, Piéme Constant Anatole ${ }^{2}$ \\ ${ }^{1}$ Department of Biochemistry, Faculty of Science, University of Douala, Douala, Cameroon \\ ${ }^{2}$ Department of Biochemistry and Physiological Sciences, Faculty of Medicine and Biochemical Sciences, University of Yaounde I, Yaounde, \\ Cameroon
}

Email address:

blancheetoundi@hotmail.fr (E. O.C. Blanche)

${ }^{*}$ Corresponding author

\section{To cite this article:}

Etoundi Omgba Cunégonde Blanche, Kayo Tayou Cynthia Valère, Mbang Mbarga Audrey Judith, Piéme Constant Anatole. Study of Acute Toxicity and the Effect of the Aqueous Extract of a Formulation of Three Edibles Mushrooms on Oxidative Stress Induced in Rats. World Journal of Food Science and Technology. Vol. 3, No. 1, 2019, pp. 6-13. doi: 10.11648/j.wjfst.20190301.12

Received: February 13, 2019; Accepted: March 20, 2019; Published: May 15, 2019

\begin{abstract}
Edible mushrooms, especially Pleurotus spp. contain a wide variety of biomolecules that can play a protective role against oxidative damage. We investigate the effect of formulation of the aqueous extract of three edibles mushrooms commonly consumed in Cameroon on oxidative stress induced in rats induced by lead acetate: Pleurotus pulmonarius, Pleurotus floridanus and Pleurotus sajor-caju. The formulation made of the three species $(1 \mathrm{w}: 1 \mathrm{w}: 1 \mathrm{w})$ were dissolved in distilled water for acute toxicity (at $2000 \mathrm{mg} / \mathrm{kg}$ of bw) and protective effect (at $400 \mathrm{mg} / \mathrm{kg}$ of bw for 21 days) against oxidative stress induced in vivo with lead acetate $(35 \mathrm{mg} / \mathrm{kg}$ of bw for 3 days). Several parameters were investigated in the serum and organs homogenous such as lipid profile, hepatic and oxidative stress markers. No particular sign of toxicity of the extract were revealed. After lead administration, significant increases were found in serum transaminases activity, creatinine, and lipid profile associated with a decrease of serum protein content and High Density Lipoprotein. In addition, significant increase in lipid peroxidation expressed as the concentration of malondialdehyde (MDA) and decreased level of reduced glutathione (GSH), superoxide dismutase (SOD) and catalase (CAT) activities in serum, liver and kidney showed oxidative stress due to lead exposure. The pre-treatment with aqueous extract of the mushroom's formulation showed protective effects against lead induced hepato-renal damage by improving antioxidant parameters, as well as ascorbic acid used as a reference. In conclusion, these mushrooms may be used as a natural source of antioxidants for food supplements against oxidative stress.
\end{abstract}

Keywords: Oxidative Stress, Acute Toxicity, Lead Acetate, Edible Mushrooms, Pleurotus spp

\section{Introduction}

Inadequate nutrition due to modern lifestyle and the increase of average longevity are the two keys reasons for the growing incidence of disease all over the world [1]. In recent years, the world of biological and medical sciences is invaded by a new concept: the "oxidative stress". It is a situation where the cell no longer controls the excessive presence of toxic oxygen radicals, where it appears a profound imbalance between pro-oxidants and antioxidants, in favor of the first, a situation that researchers imply in most human diseases [2]. Oxidative stress plays an important role in the etiology and pathogenesis of many chronic diseases such as hepatotoxicity, nephrotoxicity, atherosclerosis, hypertension, diabetes mellitus, premature aging and cancers [3]. Oxygen radicals are not only generated internally, in the organism, but also through various external sources like ultraviolet light, ionizing radiation, chemotherapeutics, inflammatory cytokines, and environmental toxins. Inhaling toxic chemicals from the environment has become unavoidable in modern civilization [1].

Antioxidants play an important role in maintaining human 
health due to their ability to scavenge these free radicals in the bodies. Fortunately, human body is designed to have its own defence system such as superoxide dismutase enzyme, glutathione enzyme and catalase to fight harmful substances and prevent cell damages. However, the consumption of supplemented antioxidants present in our diets such as in fruits, vegetables and especially in mushrooms is very important to offer adequate security [4]. In recent years, edible mushrooms have attracted attention as a commercial source of antioxidants. They might be used directly in enhancement of antioxidant defenses through dietary supplementation to reduce the level of oxidative stress [1].

The true nutritive value of mushrooms has rapidly become known and recognized not only by mushroom researchers and farmers but also by the general consumers. In addition to their good flavor, mushrooms possess favorable chemical composition with high amounts of functional proteins with an important content of essential amino acids, low total fat level, and the high proportion of polyunsaturated fatty acids (PUFA), making them well suited for low calorie diets. Edible mushrooms provide a nutritionally significant content of vitamins (B1, B2, B12, C, D, and E). Moreover, mushrooms have a low glycemic index, and high mannitol, which is especially beneficial for diabetics. Mushrooms have very low sodium $(\mathrm{Na})$ concentration, which is beneficial for hypertensive patients and a high content of potassium (K) and phosphorus $(\mathrm{P})$, which is an important orthomolecular aspect [1].

In addition to their nutritional value, some edible mushrooms have been found to be medically active in several therapies because they are rich in bioactive compounds that contain a variety of secondary metabolites including phenolic compounds, polyketides, terpenes and steroids. Different bioactive compounds of edible mushrooms are responsible for their antioxidants properties. Thus, mushrooms are considered to be a good source of natural antioxidants and seem useful as a natural source of potential antioxidant additives [5]. Besides antioxidant properties, mushrooms have received considerable attention for their biological activities, such as antitumor, antiviral, anticomplementary, anticoagulant, antidiabetic, hypolipidemic, hepatoprotective, immunostimulant and immunological activities, which made them suited for use in food, cosmetics, biomedicine, agriculture, environmental protection and wastewater management [6-7].

Thus, a number of mushrooms are considered not only as nutritionally rich food but also beneficial from the standpoint of medicinal purposes. The genus Pleurotus, commonly called oyster mushroom constitute about 40 species and all are edible. About ten species are commercially cultivated around the world. In Cameroon, the most cultivated are $P$. ostreatus, $P$. pulmonarius, $P$. sajor-caju, P. floridanus, $P$. citrinopileatus, and $P$. salmoneo-stramineus. Three species, $P$. pulmonarius, $P$. floridanus, $P$. sajor-caju, are commonly consumed due to their availability, their low cost of productivity, their high product yield and the easy cultivation procedures [8-9]. All advantages increased our interest on these species of mushrooms. Hence, the objective of this work is to determine the acute toxicity and protective effect of the aqueous extract of a formulation of three species of Pleurotus against on oxidative stress induced in rats.

\section{Methods}

\subsection{Plant Material}

Three species of oyster mushroom, $P$. pulmonarius, $P$. floridanus and $P$. sajor-caju were harvested during early mature fruiting stage in two mycicultures from Cameroon, at Pk 21, a city's suburb of Douala and at Obala in dry season. After collection, the mushrooms were individually cleaned and air-dried until dryness. Then each species of dried mushroom sample was grounded to obtain fine powder.

\subsection{Crude Extracts Preparation}

To obtain the formulation, the powder of three species of mushrooms was mixed in a proportion $1 \mathrm{w}: 1 \mathrm{w}: 1 \mathrm{w}$ in the distilled water in a proportion $1 \mathrm{w}: 6 \mathrm{v}$ and then macerated for 48h. The extract solution obtained was filtered using a filter paper and the filtrate was dried in a drying oven (brand BINDER) at $45^{\circ} \mathrm{C}$ until dryness to obtain the crude extract. The dried extract was stored at $4^{\circ} \mathrm{C}$ into a glass bottles until analysis.

\subsection{Animal's Acclimatization for Each Experiments}

Mature male and female albino Wistar rats weighing 145$200 \mathrm{~g}$ obtained from the animal Biology Department of the Faculty of Science of the University of Douala were used in this study. Animal house, were acclimatized for 2 weeks before the start of each experiment, in the laboratory of Biochemistry of the Faculty of Sciences of the University of Douala, maintained under controlled conditions of temperature $\left(23 \pm 2{ }^{\circ} \mathrm{C}\right)$ and humidity $(50 \pm 5 \%)$ and a 12 -h light-dark cycle.

The animals were housed in sanitized polypropylene cages covered with stainless steel mesh and containing sterile thick layer of chips as bedding. The bedding of the cages was changed daily and the cages were cleaned as well. They had free access to standard rat pellet diet and water ad libitum.

\subsection{Evaluation of the Extract Toxicity on Rats}

\subsubsection{Ethic of Experimentation}

These animals experimentation were carried out in strict compliance with the principles of the Declaration of Helsinki.

\subsubsection{Study of Physical and Behavioural Signs}

The protocol for the limit test proposed by the OECD (Organisation for Economic Co-operation and Development) in 2008 [10] was used to assess the acute toxicity of the prepared Extract. This Protocol recommends the administration of a single dose of $2000 \mathrm{mg} / \mathrm{kg}$ body weight (BW) of substance to a first experimental animal (rodent) followed by an observation of physiological variations of the 
animal for 48 hours. If it survives, 04 additional animals are added and receive a dose of substance at $2000 \mathrm{mg} / \mathrm{kg} \mathrm{BW}$. The observation of the physiological variations of the animal in this case is carried out for two weeks.

\subsubsection{Experimental Design}

Eight mature female albino Wistar rats were used in this experiment. The rates were divided into two groups of four rates each and treated only once by oral gavage using a gastro-esophageal probe, respectively, with distilled water $(1 \mathrm{~mL})$ for the negative control group and with the aqueous extract of the formulation prepared at a dose of $2000 \mathrm{mg} / \mathrm{kg}$ BW for the test group. Then, physical and behavioural parameters were observed for two weeks.

\subsubsection{Observing Organs and Assays of Biochemical Parameters of Toxicity}

At the end of the experiment, the rats were deprived of food overnight by 12 hours and were sacrificed by incision at the jugular vein after being anaesthetized with ketamine. Different organs were excised for macroscopic observation and blood was collected in dried test tubes. Serum was separated by centrifugation for toxicity markers analyses (ASAT, ALAT, total protein and creatinine).

\subsection{Evaluation of Effects of Aqueous Extracts on Oxidative Stress Induced in Rats}

\subsubsection{Experimental Design}

Sixteen male albino Wistar rats were used in this experiment and divided at random into four groups of four rats each treated as follows:

Group 1 - Normal control (NC) received deionised water 1 $\mathrm{ml}$ daily for 24 days

Group 2 - Positive control (Deionised water with Lead Acetate: DLA) received deionised water $1 \mathrm{ml}$ daily for 21 days followed by a solution of lead acetate $35 \mathrm{mg} / \mathrm{kg}$ bw daily for 3 days.

Group 3 - Test group (Extract with Lead Acetate: ELA) received aqueous extract $400 \mathrm{mg} / \mathrm{kg}$ bw daily for 21 days followed by lead acetate solution $35 \mathrm{mg} / \mathrm{kg}$ bw, daily for 3 days.

Group 4 - Standard group (Standard with Lead Acetate: SLA) received Ascorbic Acid solution $400 \mathrm{mg} / \mathrm{kg}$ bw for 21 days followed by lead acetate solution $35 \mathrm{mg} / \mathrm{kg}$ bw, for 3 days.

The various solutions were administered by oral gavage and animals within different treatment groups were maintained on a standard diet with free access to water.

At the end of the experimental period of 24 days, the rats were deprived of food overnight by 12 hours and all the animals were sacrificed. Blood collected were used to obtain the serum after centrifugation and stored at $-80^{\circ} \mathrm{C}$ until analyses. The liver and the kidney were excised, weighed and rinsed in saline. A segment of $1 \mathrm{~g}$ fresh liver and kidney were homogenized in Tris- $\mathrm{HCl}$ buffer ( $\mathrm{pH}$ 7.4). Homogenates were centrifuged and the resulting supernatants were divided into aliquots and stored at $-80^{\circ} \mathrm{C}$ for oxidative stress markers analysis.

\subsubsection{Biochemical Analysis}

Total proteins (TP) [11], Total cholesterol (TC) [12], High Density Lipoprotein (HDLs) [13], Low Density Lipoprotein (LDL) [13], Triglycerides (TG) [14], Creatinine (Cr) [15], Alanine Aminotransferase (ALT) and Aspartate aminotransferase (AST) [16] were determined in serum.

\subsubsection{Determination of Antioxidant Levels and Assessment of Lipid Peroxidation}

The enzyme activity of superoxide dismutase SOD [17], and catalase CAT [18], as well as the reduced glutathione GSH and Total Antioxidant Capacity (TAC) levels [19-20] were assessed in serum and in the liver and kidney homogenates. Lipid peroxides from serum and the liver and kidney homogenates were measured by the determining of TBARS formation [21].

\subsection{Statistical Analysis}

All assays were carried out in triplicates and results are expressed as mean \pm standard deviation (SD). The data was introduced in an EXCEL spreadsheet (Microsoft Office 2013) and then analyzed with the STATGRAPHICS Centurion XV version 17.1.12 software. Statistical analysis was carried out with one-way analysis of variance (ANOVA) followed by Fisher LSD post hoc test. Values of $p<0.05$ were considered significant.

\section{Results}

\subsection{Study of the Toxicity Parameters of the Extract in Rats}

\subsubsection{Observing Signs of Intoxication}

The observation for two weeks of signs of poisoning in female rats after administration of a single dose of 2000 $\mathrm{mg} / \mathrm{Kg}$ bw of extract compared to controls resulted in Table 1. It appears from this table that no signs of intoxication both physical and behavioural modifications were noted as well as no death of rats was identified. In addition, macroscopic observation of the different organs (Heart, liver, kidney, lungs, spleen, and pancreas) showed no particular signs of inflammation in female test compared with the controls.

Table 1. Change in physical and behavioural signs.

\begin{tabular}{lll}
\hline Intoxication signs & Control Group & Test group \\
\hline Locomotion & Normal & Normal \\
Reduced activity & - & - \\
Noise sensitivity & + & + \\
Breathing difficulty & - & - \\
Appetite & + & + \\
Coat & Normal & Normal \\
Urine aspect & Normal & Normal \\
Stool appearance & Normal & Normal \\
Number of deaths & 0 & 0 \\
\hline
\end{tabular}

+: yes; -: no; 0: None; $(\mathrm{n}=4)$. 


\subsubsection{Study of Biochemical Parameters of Extract Toxicity}

After observations of the organs and signs of intoxication in treated females that showed no particular signs of injury: The results of biochemical parameters related to toxicity evaluated and reported in Table 2 showed that, there were no significant differences between the AST, ALT, creatinine and total proteins between tested group and controls.

Table 2. Changes in the biochemical parameters studied for the extract toxicity.

\begin{tabular}{lllll}
\hline Groups & ALT (U/I) & AST (U/I) & Total protein (g/L) & Creatinine (mg/dL) \\
\hline Control & $6.40 \pm 0.48$ & $9.02 \pm 0.75$ & $6.31 \pm 0.30$ & $1.05 \pm 0.08$ \\
Test & $6.69 \pm 0.24$ & $8.08 \pm 0.50$ & $6.44 \pm 0.27$ & $0.98 \pm 0.05$ \\
\hline
\end{tabular}

Each value represents the mean $\pm \operatorname{SD}(\mathrm{p}<0.5)(\mathrm{n}=4)$.

\subsection{Preventive Effect of Aqueous Extract of the Formulation of the Three Species of Mushrooms Studied on Oxidative Stress Induced in Rats}

\subsubsection{Effect of Extract on Biochemical Parameters Tested in Serum}

As shown in Table 3, of the rats treated with lead acetate (DLA group) caused significant $(\mathrm{p}<0.05)$ increase in the values AST, ALT, and creatinine, when compared with the normal control group: but a significant decrease $(p<0.05)$ in total proteins level. However, AST, ALT, and creatinine levels decreased significantly $(p<0.05)$ in ELA and SLA group's animals, which received extract and standard solution before lead acetate treatment, while total proteins level increase.

Table 3. Preventive effects of extract on biochemical parameters after lead exposure in rats.

\begin{tabular}{llll}
\hline Groups & ALT $(\mathbf{U} / \mathbf{I})$ & AST $(\mathbf{U} / \mathbf{I})$ & Total proteins $(\mathrm{g} / \mathbf{L})$ \\
\hline Control & $13.10 \pm 0.71$ & $6.69 \pm 0.41$ & $18.06 \pm 0.30$ \\
DLA & $30.55 \pm 0.71^{\mathrm{a}}$ & $12.22 \pm 0.71^{\mathrm{a}}$ & $8.24 \pm 0.07^{\mathrm{a}}$ \\
ELA & $15.13 \pm 0.82^{\mathrm{ab}}$ & $8.44 \pm 0.41^{\mathrm{ab}}$ & $17.52 \pm 0.23^{\mathrm{b}}$ \\
SLA & $16.59 \pm 0.71^{\mathrm{ab}}$ & $9.17 \pm 0.36^{\mathrm{ab}}$ & $17.72 \pm 0.24^{\mathrm{b}}$ \\
\hline
\end{tabular}

Values are expressed as mean $\pm \mathrm{SD}(\mathrm{n}=4)$ in each group. Control (Deionised water only); DLA (Deionised water with Lead Acetate); ELA (Extract with Lead Acetate); SLA (Standard with Lead Acetate).

${ }^{\text {a }}$ Significantly different when compared to the control group $(\mathrm{P}<0.05)$.

bignificantly different when compared to the DLA group $(\mathrm{P}<0.05)$.

\subsubsection{Effect of Extract on Lipid Profiles Tested in Serum}

On the lipid profiles (Table 4), rats in DLA group showed significant increase $(\mathrm{p}<0.05)$ in total cholesterol, triglycerides, LDL and the LDL-C/HDL ratio, but significant decrease in HDL $(p<0.05)$, compared to those in the control group. However, total cholesterol, triglycerides, LDL and the
LDL-C/HDL ratio were significantly $(p<0.05)$ reduced in ELA and SLA groups animals and HDL were significantly increased $(p<0.05)$ compared to the DLA group animals. No significant difference is also noted between ELA and SLA groups for each parameter.

Table 4. Preventive effects of extract on lipid profiles of rats after lead exposure.

\begin{tabular}{|c|c|c|c|c|c|}
\hline Groups & Total cholesterol (mg/dL) & HDL (mg/dL) & LDL (mg/dL) & Triglyceride (mg/dL) & LDL-C/HDL \\
\hline Control & $73.25 \pm 2.99$ & $43.25 \pm 1.71$ & $18.50 \pm 1.29$ & $76.00 \pm 3.27$ & 0.43 \\
\hline DLA & $106.50 \pm 3.11^{\mathrm{a}}$ & $27.75 \pm 1.71^{\mathrm{a}}$ & $50.75 \pm 2.22^{\mathrm{a}}$ & $135.50 \pm 3.67^{\mathrm{a}}$ & 1.83 \\
\hline ELA & $87.25 \pm 4.92^{\mathrm{ab}}$ & $39.50 \pm 1.29^{\mathrm{ab}}$ & $26.25 \pm 1.71^{\mathrm{ab}}$ & $97.25 \pm 4.27^{\mathrm{ab}}$ & 0.66 \\
\hline SLA & $91.50 \pm 4.12^{\mathrm{ab}}$ & $38.50 \pm 1.73^{\mathrm{ab}}$ & $33.75 \pm 2.63^{\mathrm{ab}}$ & $104.13 \pm 4.77^{\mathrm{ab}}$ & 0.87 \\
\hline
\end{tabular}

Values are expressed as mean $\pm \mathrm{SD}(\mathrm{n}=4)$ in each group. Control (Deionised water only); DLA (Deionised water with Lead Acetate); ELA (Extract with Lead Acetate); SLA (Standard with Lead Acetate).

${ }^{\text {a }}$ Significantly different when compared to the control group $(\mathrm{P}<0.05)$.

${ }^{\mathrm{b}}$ Significantly different when compared to the DLA group $(\mathrm{P}<0.05)$.

\subsubsection{Evaluation of the Antioxidant Status Indicators}

The results of Table 5 show that in the serum, liver and kidneys, of rats treated with lead acetate (DLA group) caused significant $(\mathrm{p}<0.05)$ decrease in the following antioxidant enzymes/parameters: CAT, SOD, and GSH and in the Total Antioxidant Capacity (TAC) when compared with the control group. These parameters were significantly $(p<0.05)$ increased in ELA and SLA groups animals. In addition, the value of the biomarker of lipid peroxidation, MDA was significantly $(\mathrm{p}<0.05)$ increased in DLA group rats, compared to those in the control group. This biomarker was significantly $(\mathrm{p}<0.05)$ decreased in ELA and SLA groups animals. However, no significant difference is noted between ELA and SLA groups for each parameter. 
Table 5. Preventive effects of extract on serum, liver and kidney oxidative status indicators after lead exposure in rats.

\begin{tabular}{|c|c|c|c|c|}
\hline \multirow{2}{*}{ Antioxidant parameters } & \multicolumn{4}{|c|}{ Experimental Groups } \\
\hline & Control & DLA & ELA & SLA \\
\hline \multicolumn{5}{|l|}{ In serum } \\
\hline $\mathrm{CAT}\left(\mu \mathrm{mol} \mathrm{H}_{2} \mathrm{O}_{2} / \mathrm{mg}\right.$ of prot $)$ & $1.88 \pm 0.08$ & $0.51 \pm 0.02^{\mathrm{a}}$ & $1.27 \pm 0.06^{\mathrm{ab}}$ & $1.26 \pm 0.07^{\mathrm{ab}}$ \\
\hline $\mathrm{SOD}(\mu \mathrm{mol} / \mathrm{mg}$ of prot $)$ & $1.61 \pm 0.02$ & $0.93 \pm 0.01^{\mathrm{a}}$ & $1.44 \pm 0.02^{\mathrm{ab}}$ & $1.41 \pm 0.01^{\mathrm{ab}}$ \\
\hline $\mathrm{GSH}(\mu \mathrm{M})$ & $26.10 \pm 0.22$ & $11.89 \pm 0.15^{\mathrm{a}}$ & $18.38 \pm 0.12^{\mathrm{ab}}$ & $18.79 \pm 0.15^{\mathrm{ab}}$ \\
\hline $\mathrm{TAC}(\mathrm{mmol} / \mathrm{L})$ & $1.77 \pm 0.07$ & $0.69 \pm 0.05^{\mathrm{a}}$ & $1.64 \pm 0.02^{\mathrm{ab}}$ & $1.59 \pm 0.06^{\mathrm{ab}}$ \\
\hline $\operatorname{MDA}(\mu \mathrm{M})$ & $1.38 \pm 0.06$ & $2.32 \pm 0.05^{\mathrm{a}}$ & $1.77 \pm 0.04^{\mathrm{ab}}$ & $1.76 \pm 0.04^{\mathrm{ab}}$ \\
\hline \multicolumn{5}{|l|}{ In liver } \\
\hline $\mathrm{CAT}\left(\mu \mathrm{mol} \mathrm{H} \mathrm{H}_{2} \mathrm{O}_{2} / \mathrm{mg}\right.$ of prot $)$ & $143.03 \pm 1.80$ & $52.80 \pm 0.18^{\mathrm{a}}$ & $99.31 \pm 0.47^{\mathrm{ab}}$ & $101.74 \pm 1.09^{\mathrm{ab}}$ \\
\hline $\operatorname{SOD}(\mu \mathrm{mol} / \mathrm{mg}$ of prot $)$ & $2.52 \pm 0.15$ & $1.57 \pm 0.01^{\mathrm{a}}$ & $2.33 \pm 0.13^{\mathrm{ab}}$ & $2.19 \pm 0.12^{\mathrm{ab}}$ \\
\hline $\mathrm{GSH}(\mu \mathrm{M})$ & $19.04 \pm 0.43$ & $12.96 \pm 0.33^{\mathrm{a}}$ & $14.93 \pm 0.32^{\mathrm{ab}}$ & $14.80 \pm 0.39^{\mathrm{ab}}$ \\
\hline $\mathrm{TAC}(\mathrm{mmol} / \mathrm{L})$ & $3.70 \pm 0.17$ & $1.92 \pm 0.03^{\mathrm{a}}$ & $3.39 \pm 0.15^{\mathrm{ab}}$ & $3.35 \pm 0.14^{\mathrm{ab}}$ \\
\hline $\operatorname{MDA}(\mu \mathrm{M})$ & $1.33 \pm 0.04$ & $2.74 \pm 0.08^{\mathrm{a}}$ & $2.02 \pm 0.05^{\mathrm{ab}}$ & $2.03 \pm 0.07^{\mathrm{ab}}$ \\
\hline \multicolumn{5}{|l|}{ In kidney } \\
\hline $\mathrm{CAT}\left(\mu \mathrm{mol} \mathrm{H}_{2} \mathrm{O}_{2} / \mathrm{mg}\right.$ of prot $)$ & $79.66 \pm 0.45$ & $29.77 \pm 0.11^{\mathrm{a}}$ & $42.60 \pm 0.17^{\mathrm{ab}}$ & $42.99 \pm 0.21^{\mathrm{ab}}$ \\
\hline $\operatorname{SOD}(\mu \mathrm{mol} / \mathrm{mg}$ of prot $)$ & $2.91 \pm 0.13$ & $1.52 \pm 0.01^{\mathrm{a}}$ & $2.36 \pm 0.13^{\mathrm{ab}}$ & $2.38 \pm 0.14^{\mathrm{ab}}$ \\
\hline $\mathrm{GSH}(\mu \mathrm{M})$ & $16.42 \pm 0.07$ & $12.76 \pm 0.09^{\mathrm{a}}$ & $14.67 \pm 0.09^{\mathrm{ab}}$ & $14.74 \pm 0.09^{\mathrm{ab}}$ \\
\hline $\mathrm{TAC}(\mathrm{mmol} / \mathrm{L})$ & $3.40 \pm 0.25$ & $1.82 \pm 0.23^{\mathrm{a}}$ & $2.72 \pm 0.32^{\mathrm{ab}}$ & $2.65 \pm 0.38^{\mathrm{ab}}$ \\
\hline $\operatorname{MDA}(\mu \mathrm{M})$ & $1.01 \pm 0.01$ & $1.75 \pm 0.01^{\mathrm{a}}$ & $1.18 \pm 0.01^{\mathrm{ab}}$ & $1.21 \pm 0.01^{\mathrm{ab}}$ \\
\hline
\end{tabular}

Values are expressed as mean $\pm \mathrm{SD}(\mathrm{n}=4)$ in each group. Control (Deionised water only); DLA (Deionised water with Lead Acetate); ELA (Extract with Lead Acetate); SLA (Standard with Lead Acetate); CAT (Catalase); SOD (Superoxide Dismutase); GSH (Glutathione); TAC (Total Antioxidant Capacity); MDA (Malondialdehyde); prot (protein).

a Significantly different when compared to the control group $(\mathrm{P}<0.05)$.

${ }^{\mathrm{b}}$ Significantly different when compared to the DLA group $(\mathrm{P}<0.05)$.

\section{Discussion}

In the present study, the acute toxicity of the aqueous extract of the formulation of the three species of mushrooms studied was carried out according to the OECD protocol in 2008. The result showed no particular signs of toxicity of the extract. This result corroborates those obtained by Etoundi $e t$ $a l$. [22] who had studied the toxicity of $P$. pulmonarius and $P$. floridanus species and showed that these species are not toxic. Similarly, Ninkwango [9] had shown that oyster fungi showed no signs of toxicity. Thus, this study shows that, by formulating them, these species of fungi retain their lesser toxicity.

On the other hand, the influence of this extract on oxidative stress was studied. Oxidative stress was induced with a dose of $35 \mathrm{mg} / \mathrm{kg}$ bw of lead acetate and the preventive effect of the extract evaluated at a dose of 400 $\mathrm{mg} / \mathrm{kg}$ bw. Firstly, the results showed a significantly elevated rate of serum transaminases and creatinine in the animals treated with lead acetate (DLA group) but decreased total protein content. Anil et al. [23] and Azab [24] reported similar observations. However, these parameters were reversed by treatment with the aqueous extract used in this study. Increasing levels of AST and ALT signify damage to the structural and functional integrity of the hepatic membrane, the leakage of these enzymes from the liver cytosol into the blood stream [25]. Decreasing of serum total protein values may be attributed to a decrease in hepatic DNA and RNA induced by lead intoxication or due to decreased utilization of free amino acids for protein synthesis [26], or their degradation in amino acids and then in creatinine under the action of Serum aminotransferases [27]. The decrease in serum levels of transaminases may be due to the prevention of their leakage from the liver cytosol by the effect of the pre-administered extract, probably due to reduction in blood lead level. The increase in serum levels of total proteins may be attributed the maximum protein and essential amino acid content of the Pleurotus extract that gives them a protective effect in the face of oxidative stress through the restoration of the catalytic and structural functions of proteins as well as the regulation of their synthesis and cellular operation.

Secondly, administration of lead acetate was found to cause elevation of Total cholesterol, triglycerides and LDL. The result is in agreement with the report of Azoz and Raafat [28]. These parameters were reduced by pre-treatment with the aqueous extract of the mushroom's formulation. The high lipid levels could be due to either increased synthesis or decreased removal of lipoproteins. Decreased removal may occur because of the alteration of cell - surface receptors for lipoprotein or because of the inhibition of hepatic lipoprotein lipase activity. Furthermore, lead has been shown to depress the activity of cytochrome P-450, this can limit the biosynthesis of the bile acids, which is the significant route for elimination of cholesterol from the body [25]. Although, lead acetate caused the decrease of HDL level but pretreatment with the extract resulted in the increase of this parameter. The decrease in HDL is directly related to the lowering of good cholesterol with direct consequences for the occurrence of hypercholesterolemia-related complications [29-30]. The protective effect of the extract would result from the fact that, the fungi and their extracts could be 
considered as a new source of compounds having lowering effects of hypercholesterolemia, because they are rich in ergosterol derivatives, $\beta$-glucans and $\mathrm{HMG}-\mathrm{CoA}$ reductase enzyme inhibitors [31]. In addition, polyunsaturated fatty acids are present in sufficient quantity to bind to the bad cholesterol present in the human body and to remove it successfully from the organism [32]. Different studies describe this beneficial effect of fungi on blood cholesterol levels [33-34]. Among the different species of fungi, the Pleurotus species is distinguished as a potential regulator of cholesterol metabolism. These fungi are capable of synthesizing lovastatin, a highly lowering statin that inhibits HMG-CoA reductase, an enzyme key in regulating the biosynthesis of cholesterol in the liver [35]. Lovastatin also increases the activity of LDL-cholesterol receptors. In addition, some Pleurotus beta-glucans are able to bind to bile acids, reducing micelles formation and cholesterol absorption [36-37]. Their lowering effect was described by Jeong et al. [38], which supplemented a diet high in fat with rat fungi and found that blood cholesterol decreased in these animals compared to controls without fungi.

Finally, it was observed that levels of CAT, SOD, GSH and TAC were significantly reduced in lead acetate-treated rats. The values of these biomarkers were increased by the protective activity of the aqueous extract pre-administered, which also significantly reduced the value of the lead acetateinduced biomarker of lipid peroxidation, MDA. This result is in agreement with the report of Azoz and Raafat [28]. Reducing antioxidant enzymes may be because lead present in the organism would have affected the antioxidant barrier by inhibiting the functional thiol groups of the antioxidant enzymes [39]. Apart from targeting the sulfhydryl groups, lead can also replace the iron, copper, zinc ions or manganese that serve as important cofactors for these antioxidant enzymes and inactivate them [40]. Lipid peroxidation, another indicator of oxidative stress occurs because of the action of reactive oxygen species on lipid membranes. The generated free radical captures electrons from the lipids present inside the cell membranes and damages the cell [25]. The hepatoprotective effect of the aqueous extract would result from the antioxidant capacity of the fungi, which is generally attributed to their richness in phenolic compounds. These compounds can repair liver damage from toxins, protect against toxic agents, regenerate damaged hepatocytes and reduce inflammation [31]. Kozarski et al. [32] showed that oyster contain all the vitamins of group B, vitamins A, C, $\mathrm{D}, \mathrm{E}$, minerals and macronutrients, which are most necessary to the person. These vitamins can chelate the lead from the tissues with the restoration of the pro-oxidant/antioxidant balance. Vitamin B6 (pyridoxine) and vitamin B1 (thiamine) have essential characteristics that can cure the deleterious effects of lead toxicity. Pyridoxine is an important cofactor that participates in the metabolic pathway of transsulfurization that is responsible for the synthesis of cysteine from dietary methionine. Vitamin B6 also acts as an antioxidant by stimulating the production of GSH and as a moderate chelator [41]. Similarly, the presence of minerals in this extract would help restore the catalytic activities of the various antioxidant enzymes, since these trace elements are essential transition metals in the defence against oxidative stress, act as cofactors in enzymatic reactions in order to maintain their catalytic activity [42].

Thus, the results obtained after pre-administration of the aqueous extract, can confirm the protective effect of it at a dose of $400 \mathrm{mg} / \mathrm{Kg}$ bw, against hepato-renal damages induced by lead acetate exposure, through the presence of antioxidant compounds. In addition, the administration of a dose of vitamin $\mathrm{C}$ equivalent to that of the extract showed the same effects on the parameters studied. This may be because, vitamin $\mathrm{C}$ or ascorbic acid, is a scavenger of oxygenated free radicals that are by-products of many metabolic processes leading to oxidative stress [43]. It is probably the most widely studied vitamin in the prevention of lead acetate induced oxidative stress. Thus, its property to extinguish the ERO with metal chelation makes it a potential detoxification agent for lead [44-45].

\section{Conclusions}

This study has demonstrated that exposure to lead could have generated oxidative stress which resulted in the elevation of transaminases, creatinine in serum, and the decrease of total protein level. The lower of HDL and the increase of total cholesterol, LDL and triglycerides, as well as lipid peroxidation in the liver and kidney associated with the reduction in the antioxidant status were also obtained. The pre-treatment with the aqueous extract of the formulation of the three kind of mushrooms studied resulted in the prevention of the lead-induced hepato-renal damages and his antihyperlipemic and antioxidant properties. The protective effects of this extract may be due to the radical scavenging activity of its components demonstrated. Consequently, the aqueous extract of the formulation of the three kind of mushrooms commonly consumed in Cameroon (Pleurotus pulmonarius, Pleurotus floridanus and Pleurotus sajor-caju) could be useful in the preventive treatment of lead toxicity as well as the vitamin $\mathrm{C}$ used as a reference.

\section{Acknowledgements}

All authors would like to thank the Laboratory of Biochemistry of the Faculty of Sciences of the University of Douala for their technical platform.

\section{Declaration of Interest}

There is no conflict of interest between authors of this article.

\section{Funding}

Research funding of the Biochemistry Laboratory of the Faculty of Sciences of the University of Douala. 


\section{References}

[1] Maja K, Anita K, Dragica J, Nina T, Jovana V, Predrag P, Miomir N, Miroslav M, Vrvic, Leo van G. Antioxidants of Edible Mushrooms. Molecules. 2015. 20, 19489-19525; doi: 10.3390/molecules201019489.

[2] Kehili N, Saka S, Aouacheri O. The Safener effect of Nigel (Nigella sativa) against cadmium-induced toxicity in rats. Phototherapy. 2017. pp 1-10. DOI 10.1007/s10298-017-1099$\mathrm{y}$.

[3] Sadaf K, Mir Z, Rupal S, Sravani A. Free Radicals: Implications in Etiology of Chronic Diseases and Their Amelioration through Nutraceuticals. Pharmacologia. 2015. 6: 11-20.

[4] Arbaayah H, Umi K. Antioxidant properties in the oyster mushrooms (Pleurotus spp.) and split gill mushroom (Schizophyllum commune) ethanolic extracts, Mycosphere. 2013. 4 (4): 661-673.

[5] Boonsong S, Wanwimol K, Pongtep W. Antioxidant activities of extracts from five edible mushrooms using different extractants. Agriculture and Natural Resources. 2016. 50 $89 \mathrm{e} 97$.

[6] Kozarski M, Klaus A, Niksic M, van Griensven L, Vrvic M, Jakovljevic D. Polysaccharides of higher fungi: Biological role, structure and antioxidative activity. Chem. Ind. 2014. 68, 305-320.

[7] Loria-Kohen V, Lourenco-Nogueira T, Espinosa-Salinas I, Marin F, Soler-Rivas C, Ramirez de Molina A. Nutritional and functional properties of edible mushrooms: A food with promising health claims. J. Pharm. Nutr. Sci. 2014. 4, 187198.

[8] Djomene Y, Foudjet E, Fon D, Ninkwango T. The marketing of edible mushrooms in Cameroon. Scientific and Technical Review Forest and Environment of the Congo basin. 2017. Vol 8. pp. 65-71.

[9] Ninkwango TA. The cultivation of oyster mushrooms. Cameroon (2nd edn.). 2007. p: 47.

[10] OCDE. Test No. 425: Acute Oral Toxicity: Up-and-Down Procedure, OECD Guidelines for the Testing of Chemicals, Section 4, Éditions OCDE, 2008. Paris, https://doi.org/10.1787/9789264071049-en.

[11] Bradford M. A Rapid and Sensitive Method for the Quantitation of Microgram Quantities of Protein Utilizing the Principle of Protein-Dye Binding. Anal. Biochem. 1976. 72: 248-254.

[12] Allain C et al. Blink. Chem 1974. 20, 470. Quoted by datasheet AGAPPE. Ref: 51403007.

[13] Friedewald W et al. Clin. Chem. 1972. 18, 499. Quoted by datasheet $A G A P P E$. Ref: 51010001.

[14] Mc Gowan M, Artiss J, Standbergh D, Zak B. Clin. Chem. 1983. 29, 538. Quoted by datasheet FUTURA SYSTEM GROUP. Ref: 2704.

[15] Young D. Effects of diseases on clinical Lab. Tests, 4th ed AACC. 2001. Quoted by CYPRESS Diagnostics spec Sheet. Ref: HB0080.
[16] Kaplan L, CFSP A. Clin Chem. Mosby Ed. 1996. Quoted by datasheet SGM ITALIA. Ref: 20360.

[17] Misra H, Fridovich I. The role of superoxide anion in the autooxidation of epinephrine and a simple assay for superoxide dismutase. J Biol Chem. 1972. 247 (10): 3170-3175.

[18] Sinha A. Colorimetric Assay of catalase. Analytical Biochemistry. 1972. 47 (2): 389-94.

[19] Ellman G. Tissue sulfhydryl groups. Arch Biochem Biophys. 1959. 82: 70-77.

[20] Benzie F, Iris F and Strain J. The Ferric Reducing Ability of Plasma (FRAP) as a Measure of "Antioxidant Power": The FRAP Assay. Analytical Biochemistry. 1996. 239, 70-76.

[21] Wilbur K, Bernheim F, Shapiro O. The thiobarbituric acid reagent as a test for the oxidation of unsaturated fatty acid by various agents. Arch Biochem Biophysic. 1949. 24: 305-13.

[22] Etoundi O, Mbang M, Tuem S, Gouado I. Study of Toxicity and Antidiabetic Activity of Ethanolic and Hydroethanolic Extracts of Pleurotus pulmonarius and the Aqueous Extract of Pleurotus floridanus. J Food Nutr Popul Health. 2017. Vol. 1 No 2: 20.

[23] Anil K, Ramesh M, Monika B and Satendra K. Therapeutic Influence of Zinc and Ascorbic Acid against Lead induced Biochemical Alterations. Therapy. 2009. 64 (6): 383-388.

[24] Azab E. Hepatoprotective effect of sesame oil against lead induced liver damage in albino mice: histological and biochemical studies. Am. J. Biosci. 2014. 2 1-11.

[25] Samuel J, Herbert O, Mbagwu, Orish E. Lead Induced Hepato-renal Damage in Male Albino Rats and Effects of Activated Charcoal. Front Pharmacol. 2017. 8: 107.

[26] Moussa S and Bashandy S. Biophysical and biochemical changes in the blood of rats exposed to lead toxicity. Rom. J. Biophys. 2008. 18 123-133.

[27] Saad S, Ahlem B, Wassila A. The effect of lead acetateinduced oxidative stress on the glutathione enzyme system in rats. Ann Toxicol Anal. 2011. 23 (3): 139-145.

[28] Azoz H and Raafat R. Effect of lead toxicity on cytogenisity, biochemical constituents and tissue residue with protective role of activated charcoal and casein in male rats. Aust. J. Basic Appl. Sci. 2012. 6 497-509.

[29] Sahach V, Korkach I, Kotsiuruba A, Prysiazhna O. The inhibition of oxidative and nitrosative stresses by ecdysterone as the mechanisms of its cardio- and vasoprotective action in experimental diabetes type I. Fiziol Zh. 2008. 54: 46-54.

[30] Montonen J, Boeing H, Fritsche A, Schleicher E, Joost H, Schulze M, et al. Consumption of red meat and whole-grain bread in relation to biomarkers of obesity, inflammation, glucose metabolism and oxidative stress. Eur J Nutr. 2013. 52 (1): $337-45$.

[31] Irene R. Health and nutritional properties of fungi. A report. Technological Centre for Research on Mushroom (CTICH). 2015.

[32] Kozarski M, Klaus A, Vunduk J, Zizak Z, Niksic M, Jakovljevic D, Vrvic M, van Griensven L. Nutraceutical properties of the methanolic extract of edible mushrooms Cantharellus cibarius (French fries): primary mechanisms. Food Funct. 2015. 6, 1875-1886. 
[33] Gil-Ramirez A, Clavijo C, Palanisamy M, Soler-Rivas C, Ruiz-Rodriguez A, Marín F, Reglero G, Pérez M. Edible mushrooms as potential sources of new hypocholesterolemic compounds. Proceedings of the 7th International Conference on Mushroom Biology and Mushroom Products (ICMBMP7). 2011. 110 .

[34] Gil-Ramírez A, Clavijo C, Palanisamy M, Ruiz-Rodríguez A, Navarro-Rubio M, Pérez M, Marín F, Reglero G, Soler-Rivas C. Study on the 3-hydroxy-3-methyl-glutaryl CoA reductase inhibitory properties of Agaricus bisporus and extraction of bioactive fractions using pressurised solvent technologies. Journal of the Science of Food and Agriculture. 2013a. 93 (11): 2789-2796.

[35] Gil-Ramírez A, Clavijo C, Palanisamy M, Ruiz-Rodríguez A, Navarro-Rubio M, Marín F, Reglero G, Soler-Rivas C. Screening of edible mushrooms and extraction by pressurized water (PWE) of 3-hydroxy-3-methyl-glutaryl CoA reductase inhibitors. Journal of Functional Food. 2013b. 5 (1): 244-250.

[36] Fidge N. Fighting high cholesterol levels-lipid lowering drugs. The Medical Journal of Australia. 1993. 159: 815-819.

[37] Bobek P and Galbavy S. Effect of pleuran (beta-glucan from Pleurotus ostreatus) on the antioxidant status of the organism and on dimethylhydrazine-induced precancerous lesions in rat colon. British Journal of Biomedical Science. 2001. 58: 164168.

[38] Jeong S, Yang B, Islam R, Koyyalamudi S, Pang G, Cho K, Song C. White, button mushroom (Agaricus bisporus) lowers blood glucose and cholesterol levels in diabetic and hypercholesterolemic rats. Nutrition Research. 2010. 30 (1): 49-56.

[39] Shalan M, Mostafa M, Hassouna M, Sathishsekar D, Subramanian S. Antioxidant properties of Momordica Charantiab (bitter gourd) seeds on Streptozotocin induced diabetic rats. Asia Pac J Clin Nut. 2005. 14, 153-158.

[40] Flora S, Flora G, Saxena G, Mishra M. Arsenic and lead induced free radical generation and their reversibility following chelation. Cell Mol. Biol. 2007. 53 26-47.

[41] Ahamed M and Siddiqui M. Environmental lead toxicity and nutritional factors. Clin Nut. 2007. 26: 400-408.

[42] Sadowska-Bartosz I, Galiniak S, Bartosz G. Polyphenols protect against glycoxidation proteins. Free Radic Biol Med. 2014. 75 1: S47.

[43] Gupta M and Shari S. Lipid peroxidation and antioxidant status in patients with diabetic retinopathy. Ind. J. Physiol. Pharmacol. 2005. 49: 187-12.

[44] Tariq S. Role of ascorbic acid in free radicals trapping and toxicity of lead from Biosystems. Mol Biotechnol. 2007. 37: $62-65$.

[45] Das K and Saha S. L-ascorbic acid and alpha tocopherol supplementation and antioxidant status in nickel- or leadexposed rat brain tissue. J Basic Clin Physiol Pharmacol. 2010. 21: 325-346. 